\title{
Discussion on "Malešev, M.; Radonjanin, V.; Marinković, S. Recycled Concrete as Aggregate for Structural Concrete Production. Sustainability, 2010, 2, 1204-1225"
}

\section{Gholamreza Fathifazl $^{1, *}$ and A. Ghani Razaquur ${ }^{2}$}

1 Adjeleian Allen Rubeli Ltd., Suite \#1005, 75 Albert St., Ottawa, ON K1P 5E7, Canada

2 Centre for Effective Design of Structures, Department of Civil Engineering, McMaster University, 1280 Main Street W., Hamilton, ON L8S 4L7, Canada; E-Mail: razaqpu@ mcmaster.ca

* Author to whom correspondence should be addressed; E-Mail: gfathifazl@aar.on.ca; Tel.: +1-613-232-5786; Fax: +1-613-230-8916.

Received: 11 January 2011 / Accepted: 11 February 2011 / Published: 16 February 2011

The authors are to be congratulated for their comprehensive research work on the use of RCA as aggregate in structural grade concrete [1], but some of their conclusions with regard to the effect of aggregate type and RCA content on the fresh and hardened properties of concrete made with coarse RCA, termed RAC for brevity, need discussion.

The authors investigated the fresh and hardened properties of RAC mixes with three different RCA content levels. The sources of RCA were waste lab specimens (class C30/37) and precast concrete columns (class C40/50). The conventional concrete mix proportioning method was applied but the coarse aggregate content was modified by substituting, based on weight, $0 \%, 50 \%$ or $100 \%$ of the coarse natural aggregate by coarse RCA. Based on their test results, they concluded that concrete compressive and splitting tensile strengths are only affected by the quality of RCA rather than its quantity. In other words, the percent replacement of coarse natural aggregate by RCA does not influence the above strengths. Although the discussers agree with the authors that the compressive and tensile strengths of RAC depend on the quality of coarse RCA (properties of original concrete), other important parameters also influence to various degrees RAC concrete strength, including the relative strength of its components (original virgin aggregate and residual mortar in RCA as well as fresh mortar and natural aggregate in RAC), and the fractures properties of the interfacial transition zone (ITZ) between the natural aggregate and the residual mortar in RCA, the ITZ between the residual mortar and the fresh mortar and the ITZ between the fresh mortar and the fresh natural aggregate in RAC. According to Fathifazl et al. [2], the compressive and splitting tensile strength of RAC may be higher or lower compared to companion natural aggregate concrete (NAC) with zero replacement ratio. 
This depends on the physical and mechanical properties of the original coarse natural aggregate in RCA. If the original aggregate in RCA and the fresh aggregate in RAC were both crushed stone, the RCA particles would be less angular than the fresh aggregate particles, which would result in a RAC mix with lower strength than the companion NAC. On the other hand, if the natural aggregate in RCA and the fresh natural aggregate in RAC were both river gravel, due to the greater angularity of the RCA particles than the fresh aggregate particles, the RCA mix would have higher strength than the companion NAC. Therefore, the authors' conclusion that only the quality of RCA determines the strength of RAC is not universally valid.

The authors' conclusion that the RCA content of RAC does not affect its compressive strength is also not supported by existing research findings in the literature. According to Hansen-Narud [3], in the case of RCA with better quality residual mortar and original ITZ than the fresh mortar and its ITZ, the overall strength of RAC can be comparable to that of the companion NAC. Otherwise, RAC would have lower strength than it companion NAC. The level of reduction in strength will increase as the RCA content of RAC is increased. This is the main reason for limiting the aggregate replacement ratio to approximately 30\% [3-6]. On the other hand, it has been also shown that RAC with strength higher than the source concrete of the RCA can be produced by adjusting the w/c ratio of the fresh mortar [4-6]. In other words, if concrete strength is used as indicator of its quality, then a lower quality concrete can be recycled as aggregate to produce a higher quality RAC.

Regarding the workability of RAC, the authors stated that workability of concrete with natural and recycled aggregate is almost similar if water saturated-surface-dry RCA is used. However, according to Fathifazl [7], at constant w/c ratio; aggregate type and RCA content can affect the slump of RAC mixes. They showed that depending on the difference between the angularity of natural aggregate and RCA particles, the slump of RAC could be higher or lower than that of NAC. For instance, all other factors being the same, NAC containing only virgin river gravel as coarse aggregate would have higher slump than the companion RAC made with RCA comprising residual mortar and river gravel.

The authors also state that the shrinkage of RAC is higher than NAC for RCA content greater than $50 \%$. They also found the elastic modulus of RAC to be smaller than that of NAC for both aggregate replacement ratios. According to Table 8 of the paper, the shrinkage values were measured up to the age of 28 days, which in the opinion of the discussers, is insufficient measurement time for reaching general conclusion about the shrinkage behavior of concrete. The discussers have demonstrated through extensive testing [2] that the observed higher shrinkage and lower elastic modulus of RAC compared to NAC are generally a consequence of applying conventional mix proportioning methods to RAC and replacing some or all of the coarse natural aggregate by RCA. In fact, conventional replacement of natural aggregate with RCA, as done by the authors, generally leads to higher overall mortar (i.e., fresh plus residual mortar) volume in RAC than the NAC, and this high mortar content is the principal reason for the RCA higher shrinkage and creep and lower elastic modulus. The level of inferiority would vary, depending on the residual mortar content of RCA, but the problem can be eschewed by using a proper mix proportioning method, which considers residual mortar volume in RCA as part of total mortar volume in RAC. Therefore, the 50\% RCA content to which the authors have referred as the critical limit for shrinkage of RAC might also vary depending on residual mortar content in RCA, and recommending such a limit needs to be made a function of volumetric ratio of residual mortar in RCA. The authors have not reported the residual mortar content of the RCA that 
they have used in their tests, but as demonstrated by Fathifazl et al. [2,7,8], this quantity is critical to the design of the RAC mix and its physical and mechanical properties.

Based on their pull-out test results, the authors concluded that the bond between RAC and steel reinforcing bars is not significantly influenced by RCA, as the failure crack crosses through new cement paste. However, according to Fathifazl [7], the lower the total natural aggregate (i.e., original natural aggregate in RCA plus fresh natural aggregates) volume of RCA, the higher the likelihood of lower bond because of the reduction in the number of potential sites where the lugs of the rebars could interlock with natural aggregates in the surrounding concrete. Since conventional mix proportioning methods generally lead to an overall reduction in the total coarse natural aggregate content of RAC compared to NAC, the likelihood of reduced bond is increased. Of course, the authors test can be used to measure the relative quality of bond strength of RAC and NAC because both may have had more bond resistance than necessary but it does not mean that they had equal bond strength.

Finally, the authors reported similar elastic deflections for beams made of mixes with different aggregate replacement ratio, and consequently, concluded that RCA content has no significant influence on the flexural behavior of beams made of RAC. However, they have found higher post-cracking deflections at high RCA content level, and have attributed this to the lower modulus of elasticity of RAC compared to NAC. The authors further supported their conclusion by referring to our research results [7]. While we appreciate the authors' reference to our work, we would like to point out that the RAC mix proportioning method used in our research is a new method and is termed the "Equivalent Mortar Volume", or EMV for short, in which RCA is considered as a two-phase composite material (i.e., residual mortar and original virgin aggregate). In this approach, the volumetric ratios of residual mortar and original coarse natural aggregate in RCA are determined and these are added to the corresponding volumetric ratios of fresh mortar and fresh coarse aggregate in order to obtain the total mortar and total coarse natural aggregate content of RAC. To achieve concrete with similar properties as the companion NAC, the total mortar and total coarse natural aggregate of the two mixes are made equal. Since the EMV method is different than the conventional mix proportioning method used by the authors in their investigation, the comparison made by the authors with the discussers' research findings may not be appropriate.

\section{References}

1. Malešev, M.; Radonjanin, V.; Marinković, S. Recycled Concrete as Aggregate for Structural Concrete Production. Sustainability 2010, 2, 1204-1225.

2. Fathifazl, G.; Abbas, A.; Razaqpur, A.G.; Isgor, O.B.; Fournier, B.; Foo, S. New Mixture Proportioning Method for Concrete Made with Coarse Recycled Concrete Aggregate. J. Mater. Civ. Eng. 2009, 21, 601-611.

3. Hansen, T.C.; Narud, H. Strength of Recycled Concrete Made from Crushed Concrete Coarse Aggregate. Concr. Int. 1983, 5, 79-83.

4. Recycling of Demolished Concrete and Masonry; Hansen, T.C., Ed.; Taylor and Francis: Oxfordshire, UK, 1992; p. 316.

5. Limbachiya, M.C.; Leelawat, T.; Dhir, R.K. Use of Recycled Concrete Aggregate in High-strength Concrete. Mater. Struct. 2000, 33, 574-580. 
6. Dhir, R.K.; Limbachiya, M.C.; Leelawat, T. Suitability of recycled concrete aggregate for use in BS 5328 designated mixes. Proc. Inst. Civil Eng.-Struct. B. 1999, 134, 257-274.

7. Fathifazl, G. Structural Performance of Steel Reinforced Recycled Concrete Members. PhD Thesis, Carleton University, Ottawa, Canada, 2008.

8. Razaqpur, A.G.; Fathifazl, G.; Isgor, O.B.; Abbas, A.; Fournier, B.; Foo, S. Effect of Mixture Proportioning Method on Creep and Shrinkage of RCA Concrete. In Proceedings of the 4th International Conference on Construction Materials: Performance, Innovations and Structural Implications (CanMat '09), Nagoya, Japan, 24-26 August 2009.

(C) 2011 by the authors; licensee MDPI, Basel, Switzerland. This article is an open access article distributed under the terms and conditions of the Creative Commons Attribution license (http://creativecommons.org/licenses/by/3.0/). 